\title{
Artificial Neural Network Estimation of Thermal Insulation Value of Children's School Wear in Kuwait Classroom
}

\author{
Khaled Al-Rashidi, ${ }^{1}$ Radhi Alazmi, ${ }^{2}$ and Mubarak Alazmi ${ }^{2}$ \\ ${ }^{1}$ Technical Affairs Section, Civil Defense General Administration, 47760 Al Zahra, Kuwait \\ ${ }^{2}$ Department of Chemical Engineering, Public Authority of Applied Education and Training, College of Technological Studies, \\ 70654 Shuwaikh, Kuwait \\ Correspondence should be addressed to Khaled Al-Rashidi; r_hamad01@yahoo.com
}

Received 8 May 2015; Accepted 14 September 2015

Academic Editor: Ozgur Kisi

Copyright (C) 2015 Khaled Al-Rashidi et al. This is an open access article distributed under the Creative Commons Attribution License, which permits unrestricted use, distribution, and reproduction in any medium, provided the original work is properly cited.

Artificial neural network (ANN) was utilized to predict the thermal insulation values of children's school wear in Kuwait. The input thermal insulation data of the different children's school wear used in Kuwait classrooms were obtained from study using thermal manikins. The lowest mean squared error (MSE) value for the validation data was $1.5 \times 10^{-5}$ using one hidden layer of six neurons and one output layer. The $R^{2}$ values for the training, validation, and testing data were almost equal to 1 . The values from ANN prediction were compared with McCullough's equation and the standard tables' methods. Results suggested that the ANN is able to give more accurate prediction of the clothing thermal insulation values than the regression equation and the standard tables methods. The effect of the different input variables on the thermal insulation value was examined using Garson algorithm and sensitivity analysis and it was found that the cloths weight, the body surface area nude $\left(\mathrm{BSA}_{0}\right)$, and body surface area covered by one layer of clothing $\left(\mathrm{BSAC}_{1}\right)$ have the highest effect on the thermal insulation value with about $29 \%, 27 \%$, and $23 \%$, respectively.

\section{Introduction}

Conducting thermal comfort field experiments is a moneyand time-consuming process due to the need of sophisticated equipment to measure the environmental factors (ambient air temperature, humidity, mean radiant temperature, and air speed) and personal factors (activity level and clothing insulation). Due to cultural differences, people around the world wear different clothing ensembles. Assessing the thermal insulation values of these clothing ensembles can be done using adult-size thermal manikins which is not always available and costly. This problem became more complicated for children's clothing due to the absences of the children-size thermal manikin. To cover this lack and as an alternative method the applicability of the neural network techniques was investigated to predict the thermal insulation of the children's clothing. This investigation can also support the use of the neural network techniques in the thermal comfort, HVAC, and indoor air quality fields especially in built environment area.
Previous Research. The PMV-PPD index was established by Fanger [1] to predict the comfort thermal conditions for occupants in indoor environments. According to the index, the effects of environmental factors (ambient air temperature, humidity, mean radiant temperature, and air speed) and personal factors (activity level and clothing insulation) combination are measured to assess the occupants' thermal comfort sensations and their satisfaction with the thermal environment of the space. The insulation of the clothing in this index plays an important role in the comfort prediction method where assessing the thermal insulation value for the clothing type worn by occupants is essential to predict the occupant's thermal sensation in that space.

Many clothing research projects have been developed since 1972 for many individual items of clothing as well as several ensembles to investigate the effects of clothing on occupants' thermal comfort. The thermal insulation values of the different ensembles used in this study are based on adult measurements from standard tables for assessing thermal 
insulation values $[2,3]$. All of the previous standard tables may introduce errors if applied to children's clothing to assess the children's thermal comfort sensation.

All thermal comfort field studies were conducted in classrooms, except those of Havenith [4] and Al-Rashidi et al. [5-7], in which the estimation of children's clothing insulation values from the standard tables was based on adult measurements. McCullough et al'. study [8], which itself was based on adult clothing, was adapted by Havenith [4] to fit the children's sizes by scaling the measurements of the equation's input parameters. In McCullough et al. [9] and Al-Rashidi et al. [5-7] studies, the children's clothing insulation values were measured using adult-sized thermal manikins using children's clothing manufactured in adult's sizes.

In a comprehensive study done by Al-Rashidi et al. [10] three methods were used to determine the thermal insulation values of summer and winter school clothing ensembles worn by 6 - to 17-year-old school children, girls and boys, in Kuwait classrooms. The insulation of the different clothing ensembles was determined by measurement using adult-sized versions of the clothing on thermal manikins, estimations from adult clothing data obtained from the standards tables in $[3,11]$, and calculations using a regression equation from $\mathrm{McCullough}$ et al. [8] that was adapted by Havenith [4] to accommodate children's sizes.

The three methods were compared together and the results of this study suggested that the clothing insulation values found from the measured and adapted data were similar to the adult's data in standards tables for the same summer and winter seasons ensembles. In the last few decades, an observed secular change in the children's body surface area (McCullough et al. [9] and Al-Rashidi et al. [10]) implies that, for adolescents, the children's body surface areas are similar to those of adults, making the use of adult clothing tables even more acceptable. McCullough et al. [9] and Al-Rashidi et al. [10] in these studies give some evidence to support the applicability of using adults' data in $[3,11]$ standards to assess the thermal insulation values of different children's clothing ensembles, provided that careful selection of the garments, ensembles material, and design takes place.

Artificial Neural Network. Neural networks are models meant to mimic the biological neural systems of the human brain. Neural networks consist of an input layer, connection from the input layer to each node (neuron), and connection from the nodes to the output layer in resemblance to the structure of neurons in the human brain. The advantage of artificial neural network is its ability to compute extremely complicated nonlinear problems and find relationships between different inputs variables and the output [12].

The neural networks models were used extensively and successfully in many fields, especially in control of the HVAC systems and the indoor environment conditions such as the thermal comfort conditions inside the buildings. Few neural network studies concerned predicting the occupant's thermal comfort conditions inside buildings $[13,14]$. The occupant's clothing thermal insulation is estimated in these studies; nevertheless, to the best knowledge of the authors no neural networks models were designed to predict the occupant's clothing thermal insulation.

In this study, a neural network model was developed and designed depending on the actual clothing thermal insulation data obtained by Al-Rashidi et al. [10] for the different scholarly clothing used in Kuwait classrooms. The objectives of this study are

(1) to use the thermal insulation actual data obtained in Al-Rashidi et al. [10] study to develop and design an artificial neural network model to predict the thermal insulation of the school wear in Kuwait classrooms: the data of this study were used to train, validate, and test the ANN,

(2) to investigate the applicability of the new ANN model to predict the thermal insulation of different clothing ensembles.

\section{Methodology}

2.1. The Insulation Values of Kuwaiti School Wear. In this study, the data presented in the previous study published by Al-Rashidi et al. [10] for the scholarly girl's and boy's clothing worn in Kuwait classrooms will be used to investigate the applicability of the new ANN model. The data of insulation values of children's school wear, from 6 to 17 years of age, in Kuwait classrooms, for summer and winter using different methods, standard tables, McCullough et al.'s [8] regression equation with Havenith [4] corrections, and thermal manikins, are shown in Table 1 for girls and in Table 2 for boys.

The data in Tables 1 and 2 were selected from the original data published by Al-Rashidi et al. [10] to design the new ANN model in the next section.

2.2. Neural Network Design. MATLAB neural network toolbox was used for creating and training the neural network. A feed-forward backpropagation neural network consisted of one input layer and one hidden layer with "tansig" transfer function, and linear function output layer was selected. The input layers for the neural network are presented in Tables 1 and 2 and consisted of five variables: children's weight, children height, corrected cloth's weight, body surface area nude $\left(\mathrm{BSA}_{0}\right)$, and body surface area covered by one layer of clothing $\left(\mathrm{BSAC}_{1}\right)$.

The input data are included in Figure 1 for girl's and boy's school wear in summer and winter seasons. These inputs variables were used in McCullough et al. [8] regression equation, with Havenith [4] corrections to fit adult sizes, for calculating the intrinsic clothing insulation:

$$
\begin{aligned}
I_{\mathrm{cl}}= & 0.919+0.255 \text { weight }^{*}-0.00874 \mathrm{BSA}_{0} \\
& -0.0051 \mathrm{BSAC}_{1} \text { (clo) }
\end{aligned}
$$

where $I_{\mathrm{cl}}$ is intrinsic clothing insulation (clo); weight ${ }^{*}$ is actual clothing weight $(\mathrm{kg})$ excluding shoes $* 1.8 /$ child's body surface area $\left(A_{\mathrm{Du}}\right) ; \mathrm{BSA}_{0}$ is body surface area nude $(\%)$; $\mathrm{BSAC}_{1}$ is body surface area covered by one layer of clothing (\%). 


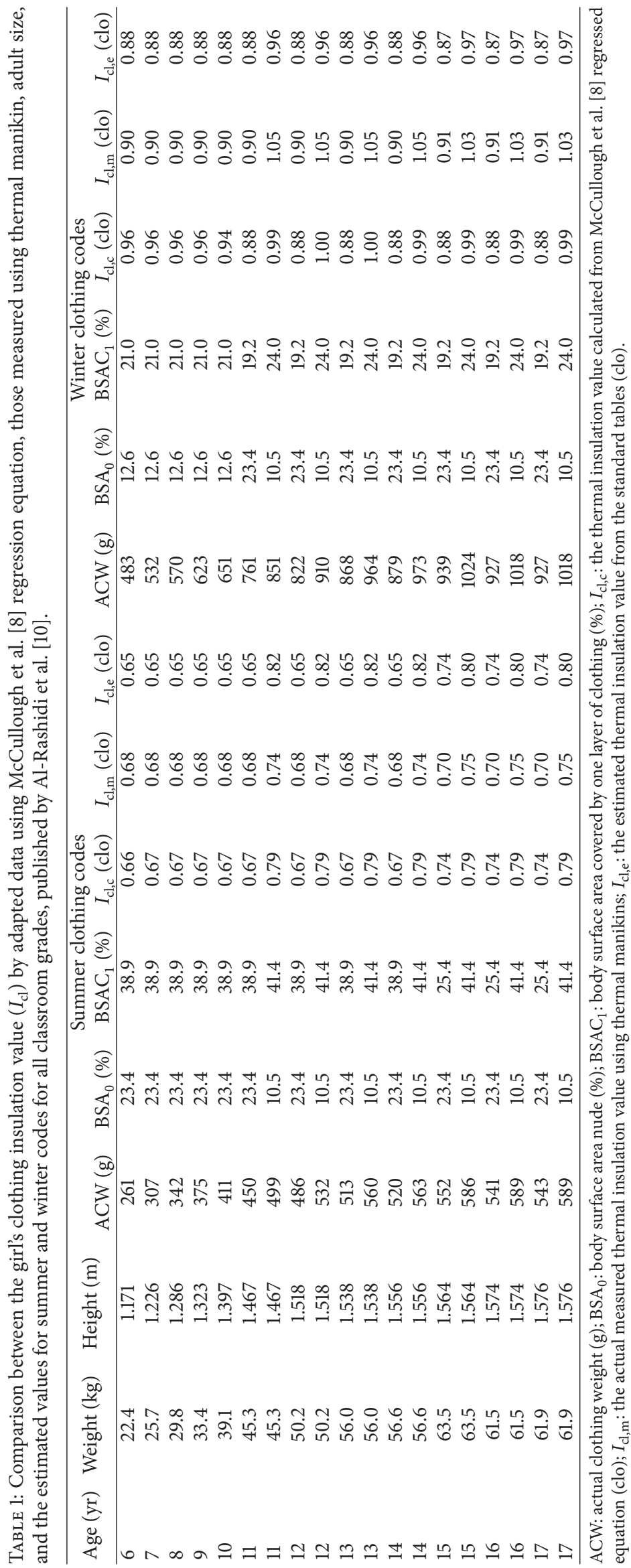




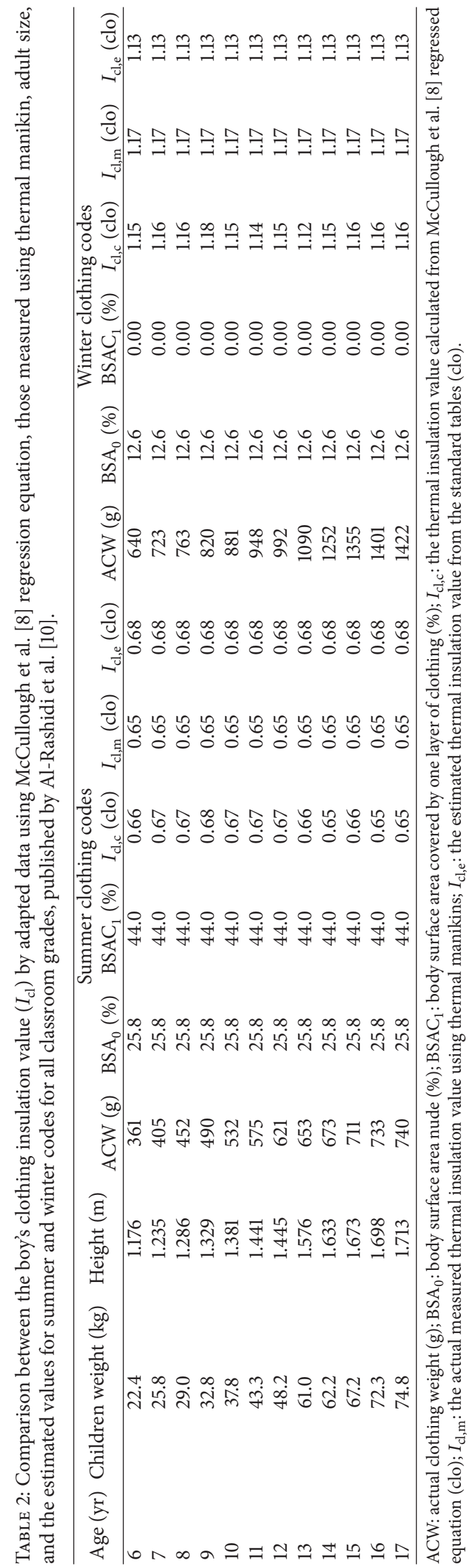




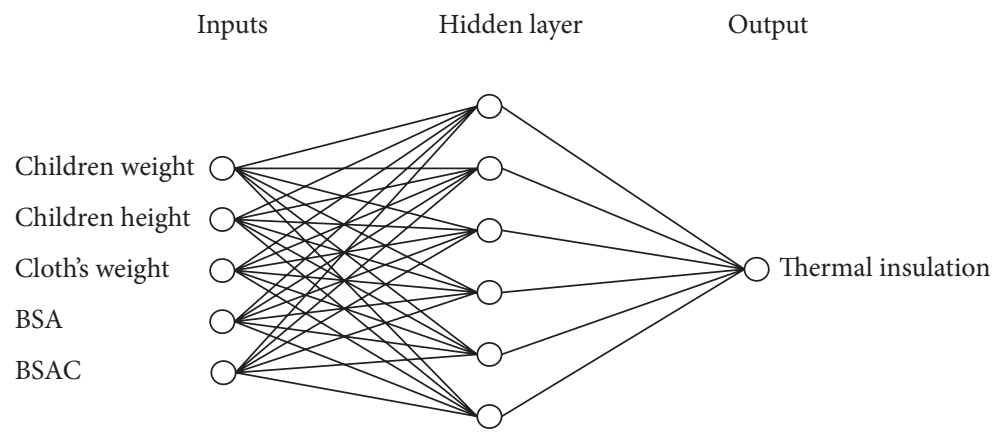

Figure 1: Neural network architecture.

The output/target variable is the actual thermal insulation measured by thermal manikin $\left(I_{\mathrm{cl}, \mathrm{m}}\right)$. The neural network was trained using Levenberg-Marquardt backpropagation "trainlm" function and "learngdm" function was used as the learning function. The neural network was trained with $70 \%$ of the data and the remaining 30\% was for validation and testing of the neural network as 15\% for validation and 15\% for testing. The hidden layer number of neurons was changed from one to nine neurons and the lowest mean squared error of $1.5 \times 10^{-5}$ was obtained with six neurons, Figure 1 .

Garson [15] equation was used to determine the relative effect of each input variable (children weight, children height, clothing weights, $\mathrm{BSA}_{0}$, and $\mathrm{BSAC}_{1}$ ) on the thermal insulation value.

2.3. Input Variables Effect Analysis. Even though ANN is considered as a "black box," in which inputs are provided to the ANN and outputs (predictions) are generated by the ANN without a clear understanding of what goes inside the ANN, several researchers developed methods to evaluate the contribution of the inputs variables to the changes in the output values [15-17]. Garson [15] developed an algorithm that uses the connection weight between each input variable and the hidden layer neurons to calculate the absolute effect of each input variable on the output result. Another method of measuring the effect of the input variables on the output variable is to perform a sensitivity analysis, in which each input variable value is changed from the lowest value to the maximum value whilst holding other input variables constant, to examine the effect of the input variables at the output variable value.

\section{Results and Discussion}

3.1. Optimization of Hidden Layer Number of Neurons. Different numbers of neurons were used to optimize the hidden layer. The best performance, with lowest mean squared error (MSE) value for the validation data, was $1.5 \times 10^{-5}$. Figure 2 shows clearly the optimum number of neurons for the hidden layers (six neurons).

The mean squared error values for the training, validation, and testing data are 0.99998, 0.99983, and 0.99986, respectively, Figure 3 . The high accuracy of the predicted values of the thermal insulation compared with the actual

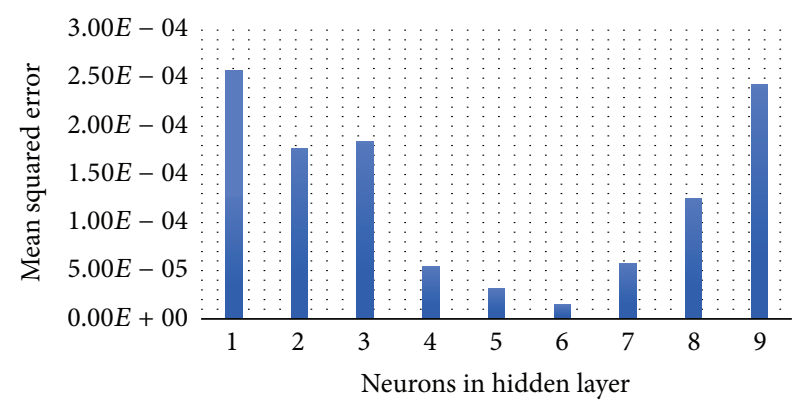

Figure 2: Optimization of the hidden layer number of neurons.

thermal insulation data from the manikin indicates that artificial neural network could be used to estimate the value of thermal insulation for children's school wear with great confidence.

3.2. Network Prediction of Thermal Insulation Values. The neural network was extremely successful in predicting the actual thermal insulation data obtained with the manikin. A high $R^{2}$ value of above 0.99 was achieved using the neural network. A comparison between the actual experimental values of the cloths thermal insulation with artificial neural network prediction reveals an almost perfect match, Figure 4.

3.3. Relative Effect of Different Input Variables. The relative effect of each input variable (children weight, children height, clothing weights, $\mathrm{BSA}_{0}$, and $\mathrm{BSAC}_{1}$ ) on the thermal insulation value is shown in Figure 5. The weight of the cloths has the highest effect on the thermal insulation value with about $29 \%$. The body surface area nude $\left(\mathrm{BSA}_{0}\right)$ and body surface area covered by one layer of clothing $\left(\mathrm{BSAC}_{1}\right)$ had less effect on the value of the thermal insulation with about $27 \%$ and $23 \%$ of the total effect, respectively. The least effect on the value of the thermal insulation was by the children weight and height.

3.4. Variables Sensitivity Analysis. ANN was used to examine the effect of changing each input variable while holding other variables at the constant average values on the thermal insulation, Table 3. The effects of changing the five input variables, children's weight, children's height, cloth's weight, 

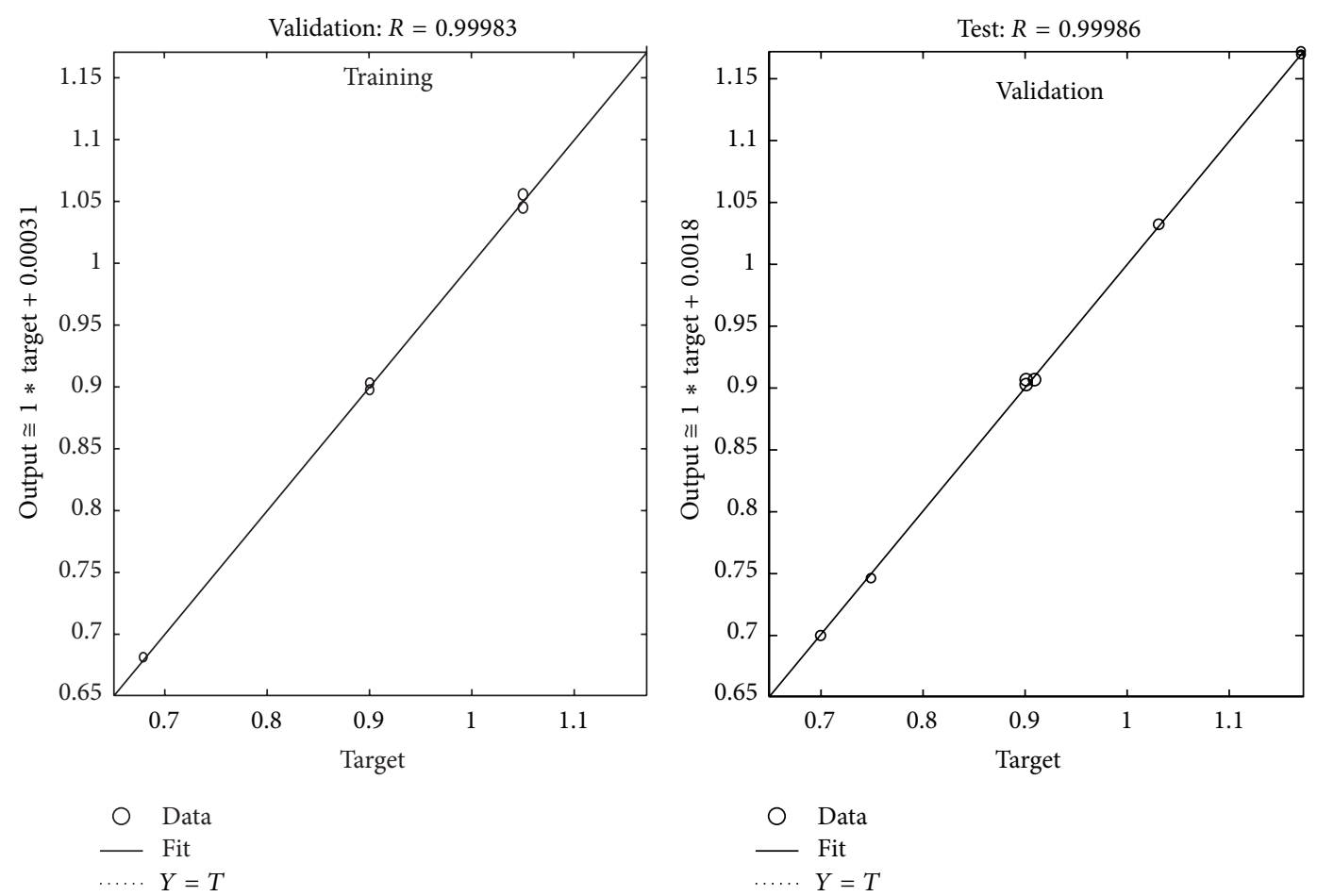

(a)

(b)

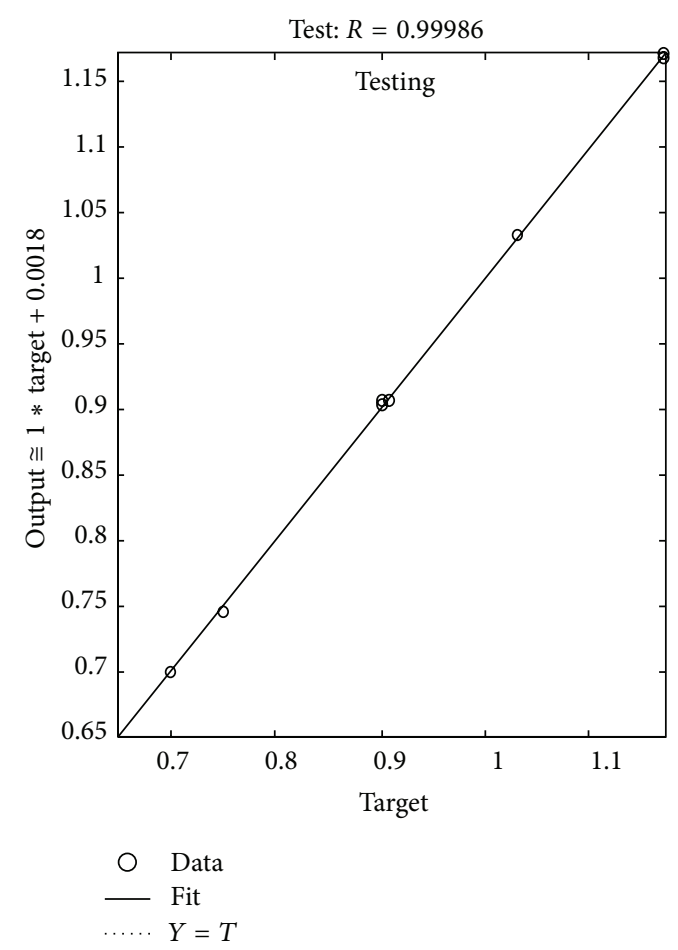

(c)

FIGURE 3: The mean squared error value for the training, validation, and testing data, respectively.

$\mathrm{BSA}_{0}$, and $\mathrm{BSAC}_{1}$, on the thermal insulation of the cloths are shown in Figures 6(a), 6(b), 6(c), 6(d), and 6(e), respectively.

Table 3 and Figures 6(a), 6(b), 6(c), 6(d), and 6(e) show that increasing children's height (from $1 \mathrm{~m}$ to $2 \mathrm{~m}$ ) and the children's weight (from $20 \mathrm{Kg}$ to $50 \mathrm{Kg}$ ) decreased the clo value predicated by the ANN model by $29 \%$ and $17 \%$, respectively. This effect can be related to the combined effect of the height and weight, considered as main factors, in calculating the body surface area $A_{\mathrm{Du}}$ (see [18]) and (1). The most noticeable increase in clo value is found with 


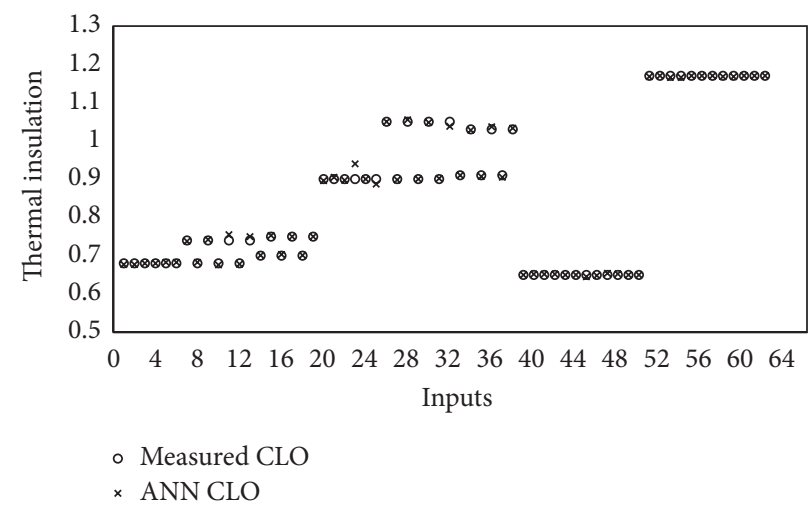

FIGURE 4: Measured thermal insulation compared with neural network prediction of thermal insulation value.

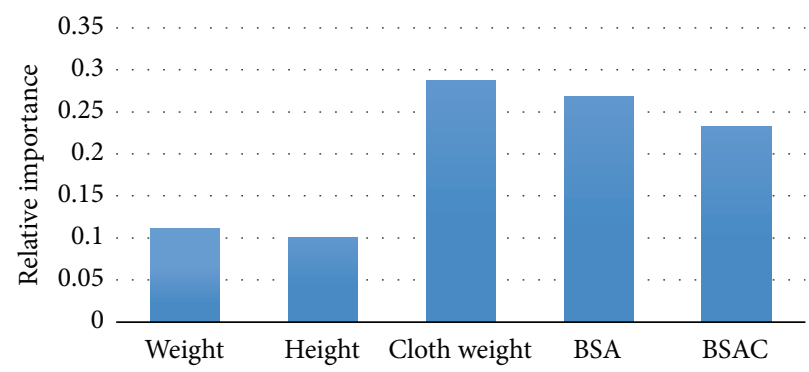

FIgURE 5: The relative importance of the input variables on the thermal insulation value.

increasing the weight of the children cloths. An increase of $88 \%$ in the value of clo from 0.64 to 1.2 was predicated by the ANN by increasing the cloth's weight from 200 grams to 1200 grams, respectively. A very slight change noticed in the clo value is predicted by the ANN with changing the $\mathrm{BSA}_{0}$ value. The value of the clo reduced by $15 \%$ from 0.85 to 0.74 with increasing the percentages of the $\mathrm{BSA}_{0}$ from 11 to 25 , respectively, which means that the more the percentages of the nude body surface areas, $\mathrm{BSA}_{0}$, are, the less the clo values will be predicted. Finally increasing the percentage of the body surface areas covered by one layer of clothing, $\mathrm{BSAC}_{1}$, resulted in large reduction in the value of clo and a decrease of $57 \%$, from 1.08 to 0.69 , was predicted by the ANN with increasing BSAC $_{1}$ value from 0 to 50 , respectively. From these findings, it can be suggested that cloths weight is the most significant and very effective factor in school wear children. All findings of this study are consistent with Garson equation relative effect analysis and Havenith [4] and Al-Rashidi et al. [10] studies.

\section{Conclusion}

Cloth's thermal insulation is one of the important variables playing an important role in predicting the thermal comfort status of occupants. Developing new artificial neural network ANN models may greatly facilitate and increases the accuracy of the clo values prediction for different clothing types. The artificial neural network model in this study was proven to
TABLE 3: Input variables range to the artificial neural network simulation.

\begin{tabular}{lccc}
\hline Variable & Minimum & Average & Maximum \\
\hline Children's weight $(\mathrm{kg})$ & 20 & 50 & 80 \\
Children's height $(\mathrm{m})$ & 1.0 & 1.5 & 2.0 \\
Cloth's weight $(\mathrm{g})$ & 200 & 700 & 1200 \\
$\mathrm{BSA}_{0}(\%)$ & 11 & 18 & 25 \\
$\mathrm{BSAC}_{1}(\%)$ & 0 & 25 & 50 \\
\hline
\end{tabular}

be capable of predicating the clo value of children's school wear with high accuracy with $R^{2}$ value above 0.99 . The weight of each variable in the neural network structure was used to estimate the relative importance of each variable on the clothing thermal insulation prediction and results indicated that the weight of the cloths has the most pronounced effect on the thermal insulation value. Moreover, $\mathrm{BSA}_{0}$ and $\mathrm{BSAC}_{1}$ had the second influential factors that affect predicting the insulation value of the cloths. The lowest effect on the thermal insulation was with changing children's weight and height. The findings of this study give evidence about the applicability of ANN models to predict the clothing thermal insulation values for children's school wear with high accuracy and support the previous work done by Havenith [4] and AlRashidi et al. [10] studies in addition to the use of the adults' data in $[3,11]$ standards to assess the thermal insulation values of different children's clothing ensembles. 


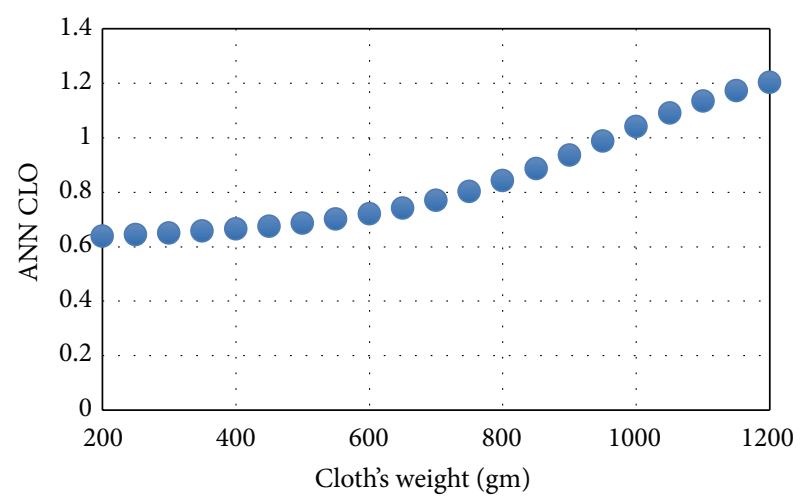

(a)

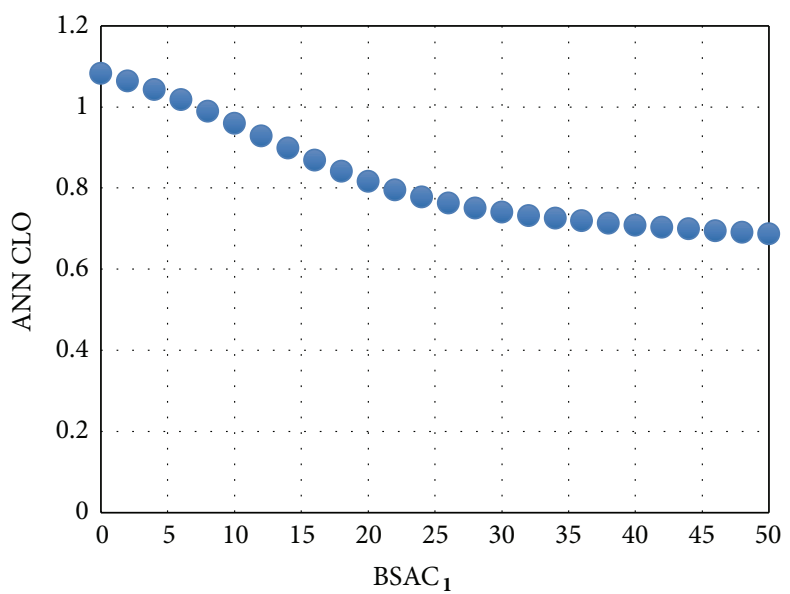

(c)

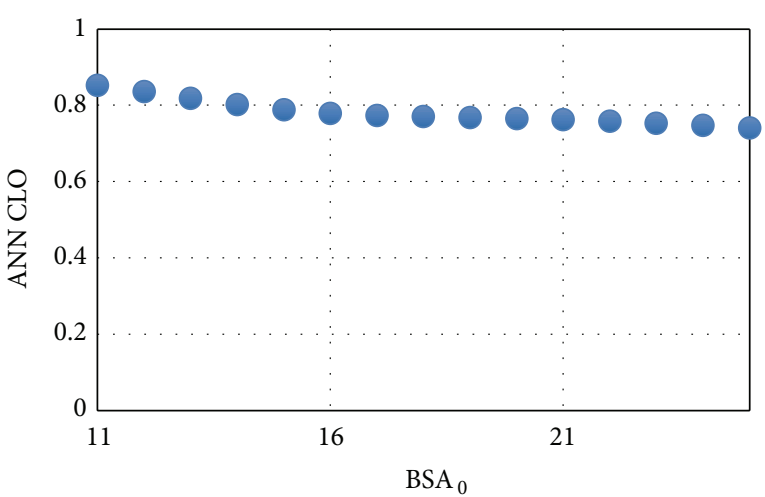

(b)

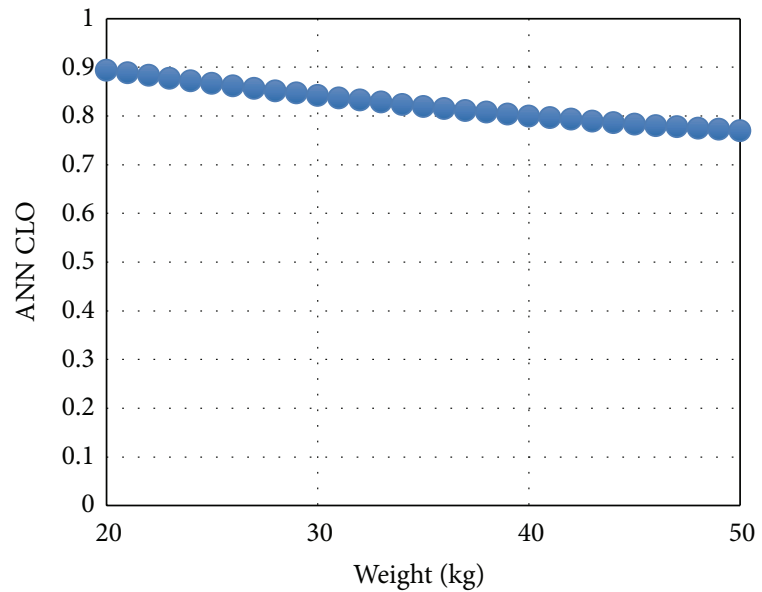

(d)

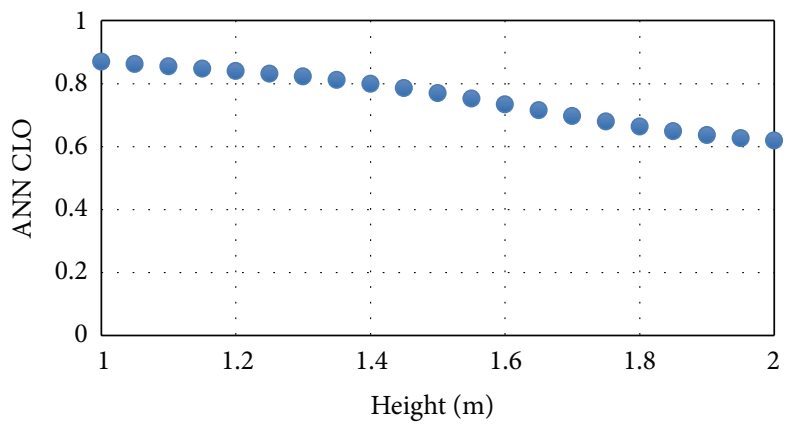

(e)

FIgURE 6: The effect of changing the five input variables, (a) children's weight, (b) children's height, (c) cloth's weight, (d) BSA , and (e) BSAC $_{1}$, on the thermal insulation of the cloths.

\section{Conflict of Interests}

The authors declare that there is no conflict of interests regarding the publication of this paper.

\section{References}

[1] P. O. Fanger, Thermal Comfort: Analysis and Applications in Environmental Engineering, McGraw-Hill, New York, NY, USA, 1972.

[2] ISO, "Moderate thermal environments-determination of the PMV and PPD indices and specification of the conditions for thermal comfort," ISO 7730, International Standards Organization, Geneva, Switzerland, 2005.

[3] ASHRAE 55, Thermal Environmental Conditions for Human Occupancy, ANSI/ASHRAE Standard 55-2004, American Society of Heating, Refrigerating, and Air-Conditioning Engineers, Atlanta, Georgia, 2013.

[4] G. Havenith, "Metabolic rate and clothing insulation data of children and adolescents during various school activities," Ergonomics, vol. 50, no. 10, pp. 1689-1701, 2007.

[5] K. E. Al-Rashidi, D. L. Loveday, and N. K. Al-Mutawa, "Investigating the applicability of different thermal comfort models in Kuwait classrooms operated in hybrid air-conditioning mode," 
in Sustainability in Energy and Buildings, pp. 347-355, Springer, Berlin, Germany, 2009.

[6] K. E. Al-Rashidi, D. L. Loveday, and N. K. Al-Mutawa, "Investigating the applicability of different thermal comfort models in naturally ventilated classrooms in Kuwait," in Proceedings of the Engineering Congress on Alternative Energy Applications (EC '09), Kuwait City, Kuwait, November 2009.

[7] K. E. Al-Rashidi, D. L. Loveday, and N. K. Al-Mutawa, "Investigating the applicability of different thermal comfort models in air-conditioned classrooms in Kuwait," in Proceedings of the 10th Rehva World Congress-Clima 2010, Sustainable Energy Use in Buildings, Antalya, Turkey, May 2010.

[8] E. McCullough, B. Jones, and J. Huck, "A comprehensive data base for estimating clothing insulation," ASHRAE Transactions A, vol. 91, no. 2, pp. 29-47, 1985.

[9] E. A. McCullough, S. Eckels, and C. Harms, "Determining temperature ratings for children's cold weather clothing," Applied Ergonomics, vol. 40, no. 5, pp. 870-877, 2009.

[10] K. E. Al-Rashidi, D. L. loveday, N. K. Al-Mutawa, and G. Havenith, "A comparison of methods for assessing the thermal insulation value of children's schoolwear in Kuwait," Applied Ergonomics, vol. 43, no. 1, pp. 203-210, 2012.

[11] International Organization for Standardization, "Ergonomics of the thermal environment-estimation of the thermal insulation and evaporative resistance of a clothing ensemble," ISO 9920, International Organization for Standardization, Geneva, Switzerland, 2007.

[12] I. A. Basheer and M. Hajmeer, "Artificial neural networks: fundamentals, computing, design, and application," Journal of Microbiological Methods, vol. 43, no. 1, pp. 3-31, 2000.

[13] X. Luo, W. Hou, Y. Li, and Z. Wang, "A fuzzy neural network model for predicting clothing thermal comfort," Computers \& Mathematics with Applications, vol. 53, no. 12, pp. 1840-1846, 2007.

[14] W. Liu, Z. Lian, and B. Zhao, "A neural network evaluation model for individual thermal comfort," Energy and Buildings, vol. 39, no. 10, pp. 1115-1122, 2007.

[15] G. D. Garson, "Interpreting neural-network connection weights," Artificial Intelligence Expert, vol. 6, no. 4, pp. 47-51, 1991.

[16] A. T. C. Goh, "Back-propagation neural networks for modeling complex systems," Artificial Intelligence in Engineering, vol. 9, no. 3, pp. 143-151, 1995.

[17] S. L. Özesmi and U. Özesmi, "An artificial neural network approach to spatial habitat modelling with interspecific interaction," Ecological Modelling, vol. 116, no. 1, pp. 15-31, 1999.

[18] D. Du Bois and E. F. Du Bois, "A formula to estimate the approximate surface area if height and weight be known," Archives of Internal Medicine, vol. 17, pp. 863-871, 1916. 

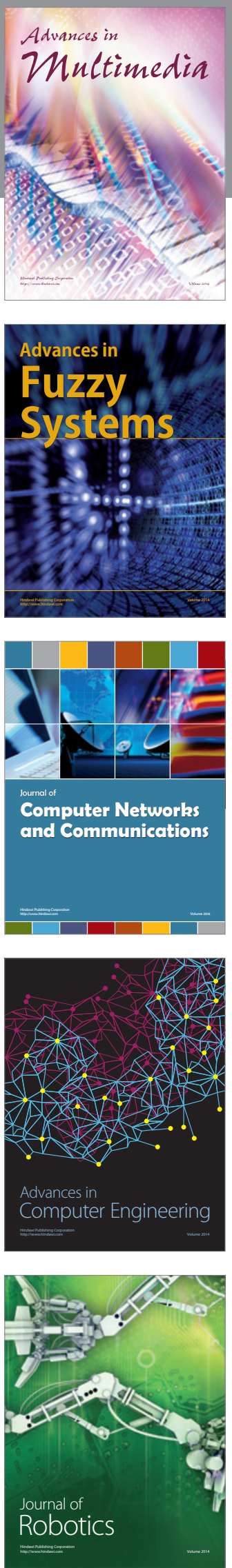

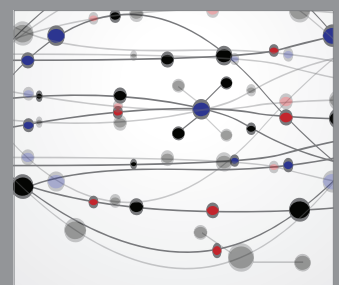

The Scientific World Journal
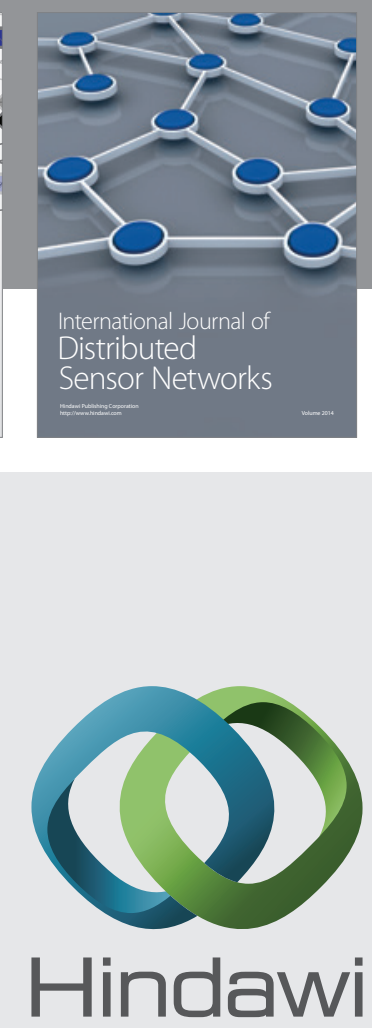

Submit your manuscripts at

http://www.hindawi.com
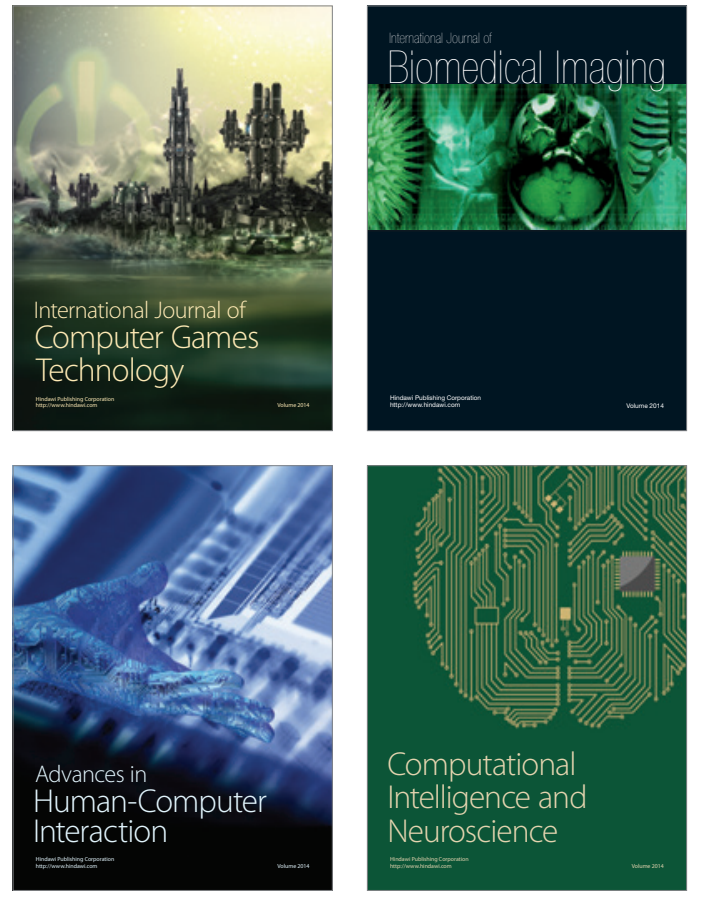
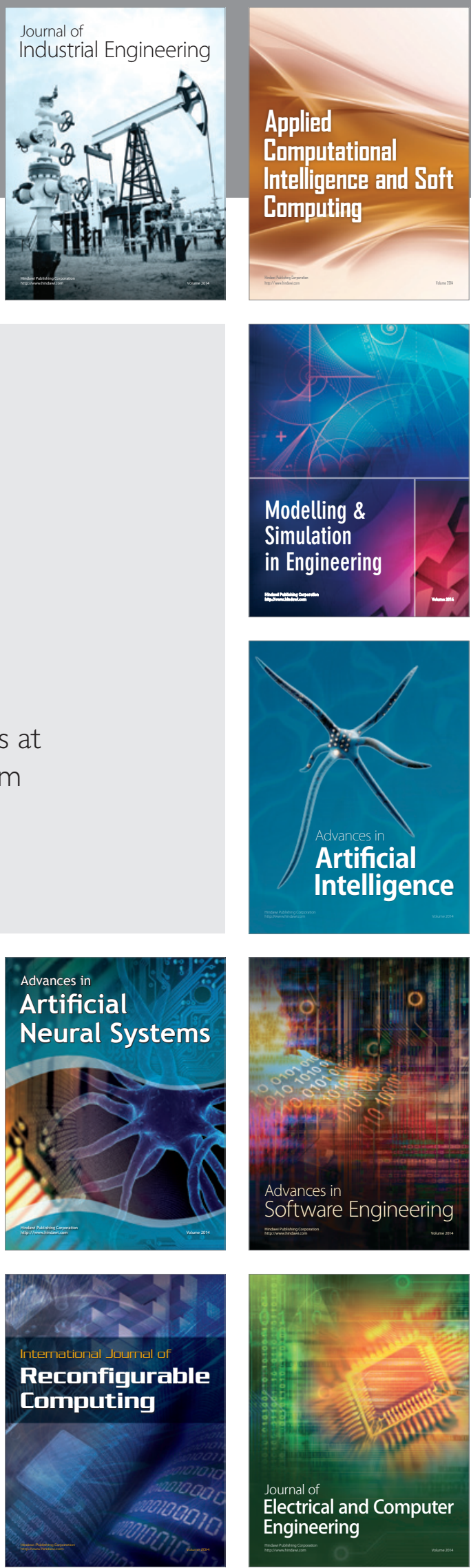